\title{
The Policy of Preemption and Its Consequences: Iraq and Beyond
}

\author{
Philip T. Dunwoody \\ Juniata College \\ Kenneth R. Hammond \\ University of Colorado, Boulder
}

\begin{abstract}
In this article we apply research in the field of judgment and decision making to the policy of preemption. We use Brunswik's lens model to frame the policy of preemption as the integration of multiple fallible indicators under conditions of uncertainty. We use the Taylor-Russell diagram to demonstrate how the policy of preemption increases judgment uncertainty and error. The continuation of a policy of preemption will inevitably lead to an increase in false positives (mistaken military engagements), an increase in tension and dispute among U.S. allies (and foes) over these engagements, and a growing world perception that the United States is an aggressor nation. Post-9/11 policymakers and the public are explicitly focused on reducing false negatives at the implicit cost of increasing false positives. Greater appreciation of the inverse relationship between false positives and false negatives is needed to understand the consequences of the policy of preemption.
\end{abstract}

The administration of U.S. President George W. Bush made an important policy shift in the 2002 National Security Strategy (NSS) of the United States of America with regard to the criteria for military engagement. The NSS argues that "[t]he struggle against global terrorism is different from any other war in our history" (section III) and that this new threat requires a dramatic shift from a "reactive posture" (section V) to one of "acting preemptively" (section III). The preemptive focus of the 2002 NSS can be seen in the following statements:

Correspondence should be addressed to Philip T. Dunwoody, Assistant Professor, Department of Psychology, Good Hall, Juniata College, 1700 Moore Street, Huntingdon, PA 16652. E-mail: drdunwoody@yahoo.com 
the United States can no longer solely rely on a reactive posture as we have in the past....The greater the threat, the greater is the risk of inaction and the more compelling the case for taking anticipatory action to defend ourselves, even if uncertainty remains as to the time and place of the enemy's attack. (section V)

These statements are in sharp contrast with the past century of military engagement, which has been dominated by struggles over territory and ideology. Wars were typically fought to take and defend territory. The first Gulf War of 1991 is an excellent example of a military engagement where territory played a central role. The reasons for U.S. military engagement were clear (Iraq invaded Kuwait) and, consequently, world opinion characterizing the situation was fairly unified. But if the first Gulf War, Operation Desert Storm, is contrasted with the U.S. military engagement of Iraq in 2003, Operation Iraqi Freedom, sharp differences arise. The reasons for U.S. military engagement were considerably less clear and there was great variability in world opinion characterizing the situation. We believe this increase in disagreement is a direct and predictable result of the U.S. policy shift from a "reactive" posture to a "preemptive" one. Increased disagreement is inevitable with this policy shift, but so also is an increase in false positives; that is, taking military action when it is not warranted.

Since WWII, the United States has relied primarily on the policy of Mutually Assured Destruction (which was indifferent to false positives), which restrained action and allowed the United States to maintain a reactive policy. But terrorists, who often seek martyrdom, may not be deterred by the retaliatory threat of death. In his 2003 State of the Union speech President Bush asked, "Since when have terrorists and tyrants announced their intentions, politely putting us on notice before they strike?" This rhetorical question underscores the perspective that a reactive policy is now inadequate. U.S. Secretary of State Colin Powell made a similar argument to the United Nations (UN) on February 6, 2003, to justify the invasion of Iraq:

Given Saddam Hussein's history of aggression, given what we know of his grandiose plans, given what we know of his terrorist associations and given his determination to exact revenge on those who oppose him, should we take the risk that he will not some day use these weapons at a time and the place and in the manner of his choosing at a time when the world is in a much weaker position to respond? The United States will not and cannot run that risk to the American people. Leaving Saddam Hussein in possession of weapons of mass destruction for a few more months or years is not an option, not in a post-September 11th world.

The Bush administration had clearly decided that the costs of inaction would exceed the costs of action. They chose to act despite the inherent uncertainty in judging the intentions and predicting the actions of others. That choice apparently rested on 
the judgment that the high potential costs of false negatives exceeded the high potential costs of false positives. But were the two costs ever explicitly compared?

The shift to a more preemptive policy means that in the future prediction and judgments about another's intention will play a more central role in decisions about military engagement. However, prediction inherently involves human judgment, and thus demands consideration of uncertainty. Due to this policy shift, research in the field of judgment and decision making is now of paramount importance for understanding the policy of preemption and its consequences. In this article we are not attempting to condemn or condone this policy shift, but rather to explicate its likely consequences from a more complete analytical perspective than is ordinarily applied to geopolitical decisions of this kind. We use Brunswik's lens model and the Taylor-Russell diagram as our tools for this more analytic understanding.

\section{BRUNSWIK'S LENS MODEL}

Brunswik's lens model is a perception-inspired model of human judgment (see Brunswik, 1952; Hammond, 1996; Hammond \& Stewart, 2001) that has previously been applied to threat assessment scenarios (e.g., Adelman, Miller, Henderson, \& Schoelles, 2003; Dunwoody, Haarbauer, Mahan, Marino, \& Tang, 2000; Hollenbeck et al., 1995). The policy of preemption fundamentally relies on the integration of multiple fallible indicators to form a threat assessment of a particular group. Only after this threat assessment is a decision made about preemption. Figure 1 depicts Brunswik's lens model as applied to ascertaining the threat level of a potentially hostile group based largely on intelligence. The row of ellipses located in the center of the figure represents a number of fallible indicators that an individual or group may use as a basis for their threat assessments. The right hand side of Figure 1 depicts the integration of these fallible indicators into an overall threat assessment by a judge. The weight given to any particular indicator may vary between individuals and situations. Brunswik's lens model is symmetric in that an attempt is made not only to model how a judge integrates indicators, as depicted on the right hand side of the model, but also to model how the indicators relate to the criterion, as depicted on the left hand side of the model, labeled "ecology." The overall accuracy of the judge, labeled "achievement" in Figure 1, is assessed by comparing the judgments, in this case the perceived threat, with a criterion, in this case the actual threat. In many scenarios there is no clear criterion available to assess the accuracy of a judgment. However, the model is still conceptually useful for understanding how a judge attempts to infer some distal state, actual threat, on the basis of a variety of more proximal and fallible indicators.

Threat assessment of a group involves the use of many indicators (commonly referred to as intelligence), some of which are labeled in the center of Figure 1. "Humint" stands for human intelligence and includes all human sources of infor- 


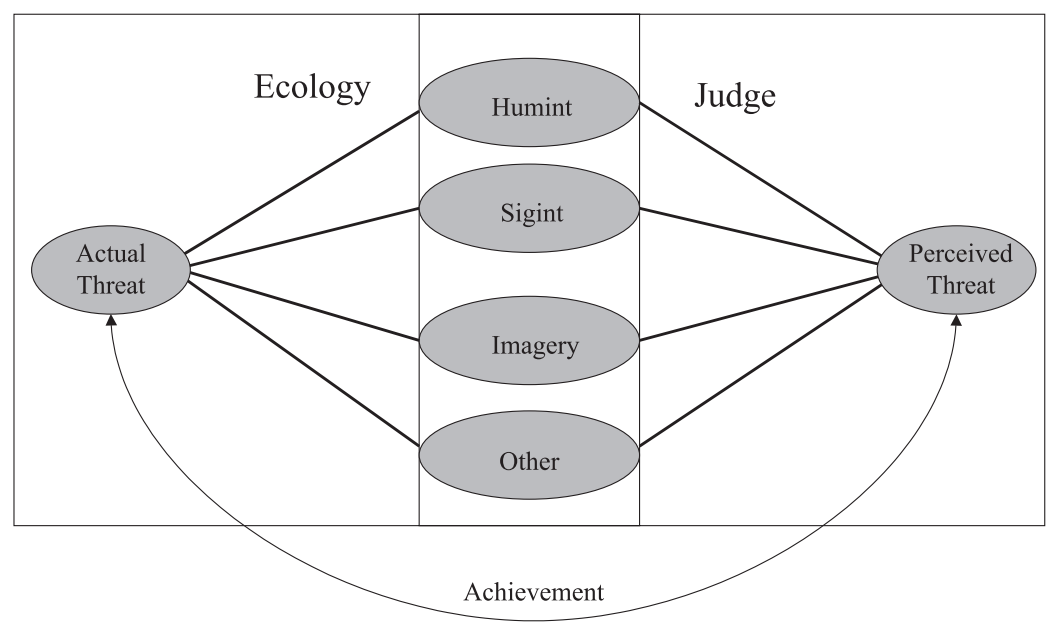

FIGURE 1 Threat assessment via Brunswik's lens model.

mation, such as secret agents, political exiles, and opposition groups. "Sigint" stands for signals intelligence and includes the interception of communications as well as measures of communication traffic. "Imager" refers to any imagery techniques, such as the U2 plane and satellite photography (Herman, 2003).

One characteristic of Brunswik's lens model and theory is that a judge may differentially utilize indicators when attempting to infer some distal state, a practice Egon Brunswik termed vicarious functioning. For example, the United States relied heavily on human intelligence sources to infer Iraq's WMD program until the UN inspectors left Iraq. At this point the United States was forced to rely more on satellite imagery because it no longer had human information sources. Vicarious functioning in this case resulted in a decrease in the accuracy of judgment because threat assessment shifted from using a less fallible indicator, human intelligence, to a more fallible indicator, satellite imagery. Some indicators will necessarily be better predictors of the distal state than others and a good judge will rely on indicators based on their ability to accurately predict the distal state. Judgment accuracy will depend on the quality and quantity of indicators available and their appropriate use by a judge.

Brunswik's lens model can be partitioned into the judge side and the ecology side so that a scatter plot of the relationship between actual threat and perceived threat may be formed. Figure 2 represents this theoretical scatter plot with an ellipse representing the approximate distribution of points in the scatter plot. This ellipse represents achievement from Figure 1 and is assumed here to be a significant positive relationship. It is important to note that many different fallible indicators combine into a unidimensional assessment of threat. We have explicitly mentioned 


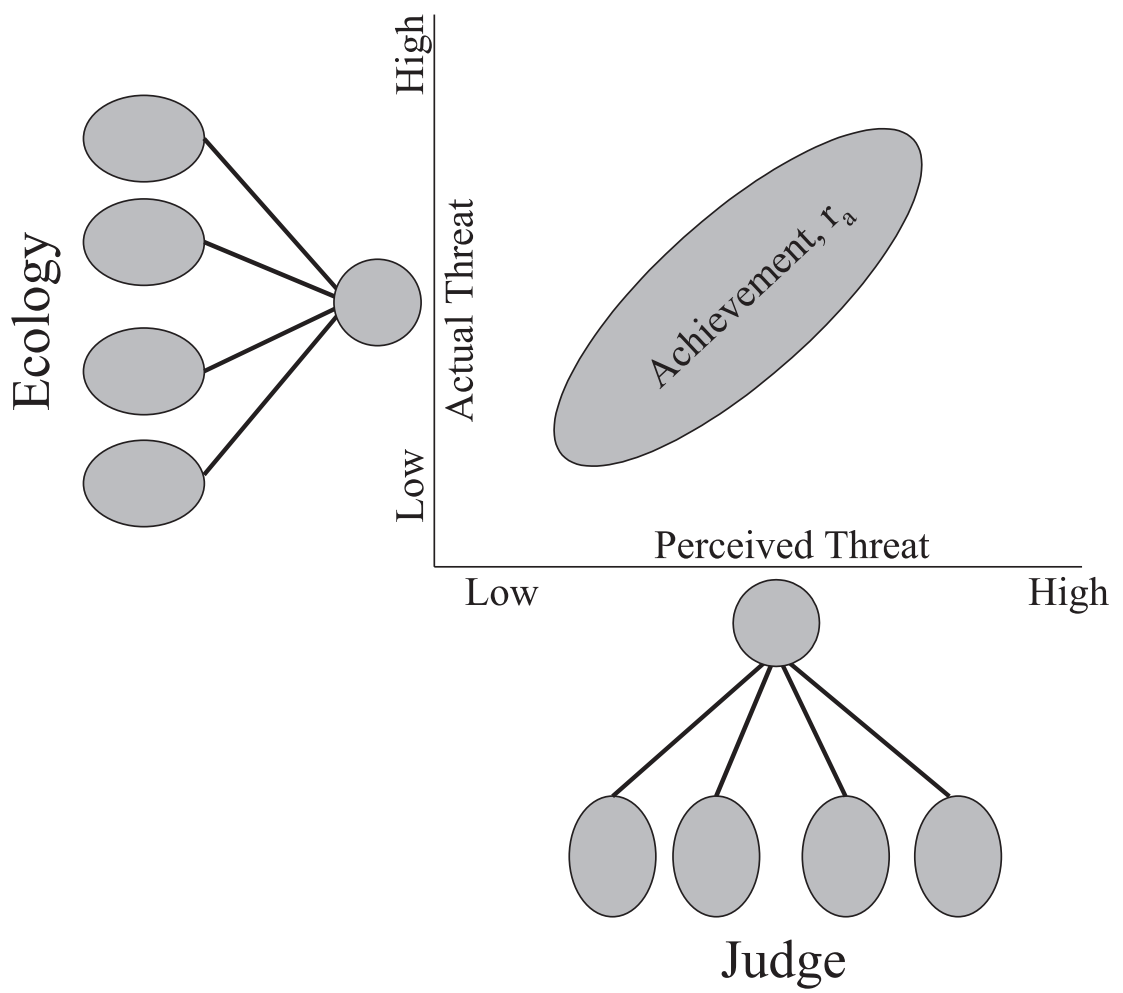

FIGURE 2 The lens models and the relationship of perceived threat to actual threat.

only a few intelligence variables (Humint, Sigint, and Imager in Figure 1) but there are other variables that would likely contribute to threat assessments such as past behavior, violations of UN resolutions, and more. Furthermore, decisions of war can include more than just threat assessment, such as sending a signal to other nations not directly involved in the conflict. For example, the decision to engage in Operation Iraqi Freedom may have also been motivated by the desire to demonstrate to the world that the war on terror is a global war and not limited to actions in Afghanistan. Clearly decisions of military engagement often involve multiple and interacting variables. Because the policy of preemption explicitly focuses on future threats, we limit our discussion to threat assessment. However, other variables of interest could be examined in a similar manner and combined with perceived threat for an even broader understanding of decisions about military engagement utilizing this framework.

Brunswik's lens model depicts the basis of the policy of preemption as threat assessment based on the integration of multiple fallible indicators under conditions 
of irreducible uncertainty. The accuracy of these threat assessments will necessarily be limited by the quality and quantity of the indicators available and their appropriate use by a judge. When a valid indicator is no longer available, such as when the UN inspectors left Iraq, mistakes will be more likely. The inferential process of determining a distal state based on proximal indicators is inherently fallible and now serves as the basis of the U.S. policy of preemption.

\section{TAYLOR-RUSSELL DIAGRAM}

While Brunswik's lens model depicts judgment based on multiple fallible indicators, the Taylor-Russell diagram explains the relationship among outcomes of a dichotomous decision that are based on a prior judgment. Specifically, the policy of preemption involves at least two important steps. Step one is making a judgment about the threat level of a group, which we describe using Brunswik's lens model, and step two is deciding what course of action should be taken based on the judgment of threat. It is this second step that the Taylor-Russell diagram helps clarify.

The Taylor-Russell diagram (see Figure 3) was introduced by Taylor and Russell in 1939 and has a long history as a conceptual framework for understanding decisions involving prediction (Taylor \& Russell, 1939). Hammond

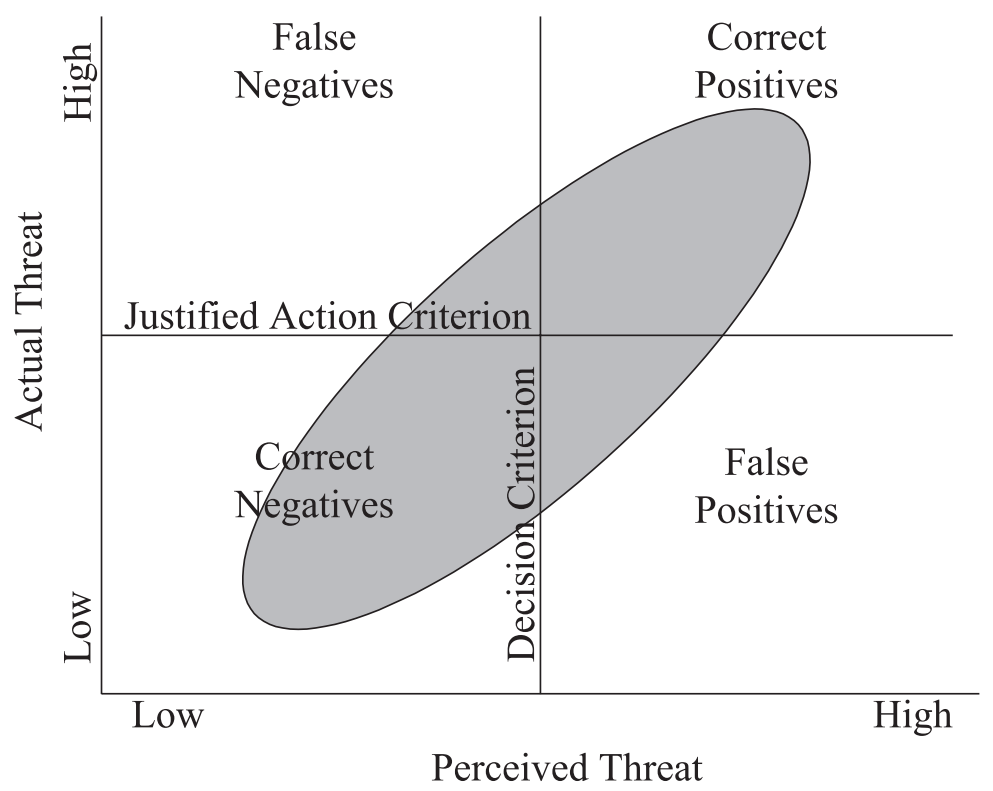

FIGURE 3 The Taylor-Russell diagram. 
(1996) and Stewart (2000) point out that "it applies to virtually any policy problem where decisions must be made in the face of uncertainty" (Stewart, 2000, p. 46). We use the Taylor-Russell diagram to explicate the consequences of a preemptive decision.

The vertical axis in Figure 3 represents the unknowable truth of the situation, that is, the actual threat posed by a rogue state or group. This actual threat level is naturally a continuum, but at some point (which we can only infer) the threat level becomes significant enough to justify military action. The horizontal bar (labeled "Justified Action Criterion" or JAC as in Figure 4) in the diagram represents this unknowable criterion. The justifiable point of military engagement is never known with certainty because a group's actual threat level is never known for certain. Some groups may desire to appear more or less threatening than they actually are and therefore actual threat level is something that can only be estimated based on the available intelligence. The horizontal axis represents the perceived threat level posed by a group. Perceived threat level is based on available intelligence, to be ascertained by judgments based on fallible indicators. At some point, a decision is made that the perceived threat level is significant enough to warrant military action. The vertical bar (labeled "Decision Criterion") represents this decision point and is the criterion for military engagement based on the perceived threat level.

Figure 2 forms the basis for understanding the Taylor-Russell diagram and its relationship to Brunswik's lens model. The ellipse in Figures 2 and 3 represents a hypothetical scatter plot distribution of perceived and actual threat from Figure 1. The ellipse represents all groups, countries, or persons that could potentially be a

Old Reactive Policy

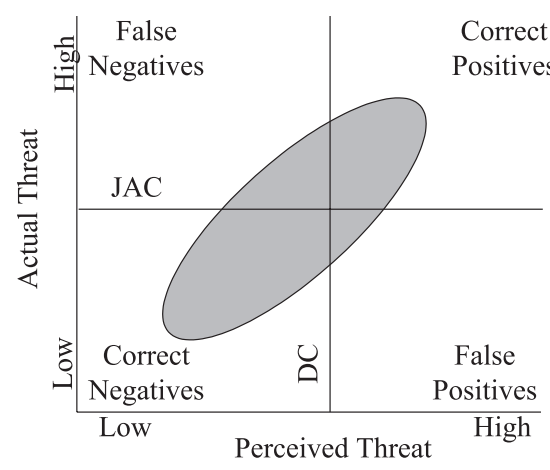

New Preemptive Policy

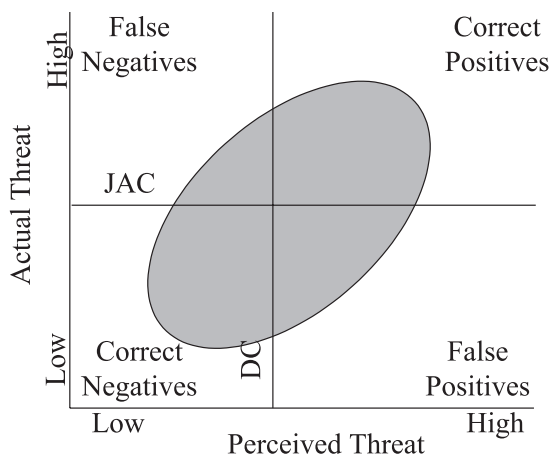

FIGURE 4 A comparison of old and new policies via the Taylor-Russell diagram. 
terrorist threat. Some groups will truly be a significant threat because they are planning terrorist acts or supporting terrorists. These groups are represented by the proportion of the ellipse falling above the horizontal bar labeled JAC. Some groups will not be a significant threat and are represented by the portion of the ellipse falling below the horizontal bar labeled JAC. The width of the ellipse represents the relationship between the perceived threat level and the actual threat level. If the perceived threat level closely reflects the actual threat level (i.e., if there is substantial valid intelligence) then the width of the ellipse is narrow, indicating a strong relationship between the two axes. As the actual threat level becomes more difficult to predict from the perceived threat level (limited intelligence of poor validity), the width of the ellipse grows, indicating greater uncertainty in the system. Note that territorial intrusions reduce uncertainty to zero.

The four cells of the Taylor-Russell diagram represent the four possible outcomes of a decision about military engagement. The bottom left cell contains correct negatives. A correct negative is obtained when the perceived threat level is below the criterion for military engagement (the vertical bar labeled "Decision Criterion") and the actual threat level is below the always unknowable justifiable point of military engagement (the horizontal bar labeled JAC). In other words, a correct decision is made not to take military action. The upper right cell represents the correct positives. A correct positive occurs when the actual threat level is high and the threat level is judged to be high enough to justify military engagement. The other two cells represent errors. The upper left cell consists of the error of false negatives. A false negative occurs when a group is inaccurately perceived as not being a significant threat.

The Taylor-Russell diagram illustrates how decision outcomes, specifically decisions about military preemption, are largely influenced by three factors: uncertainty in the judgment context (the width of the ellipse), the justified action criterion (at what point is a group really a threat?), and the decision criterion (how much evidence is needed to take military action?; Stewart, 2000). An important point that the Taylor-Russell diagram makes clear is that the two types of error, false positives and false negatives, are inversely related. Given a particular level of uncertainty, reducing false negatives by lowering the decision criteria must increase false positives and vice versa. This "duality of error" is fundamental to understanding the tradeoffs involved in the policy of preemption and is addressed in detail next.

\section{COMPARING OLD AND NEW POLICIES AND THEIR IMPLICATIONS}

A reactive policy implies that perceived threat is based largely on actions taken by the other party. Sometimes these actions are easily verifiable (e.g., Iraq clearly invaded Kuwait; the Japanese clearly attacked Pearl Harbor). However, the 2002 
NSS now indicates "America will act against such emerging threats before they are fully formed" (NSS, 2002, introduction) based largely on intelligence reports. The NSS acknowledges the increased role of intelligence gathering under the policy of preemption. The 2002 NSS states, "Intelligence and how we use it is our first line of defense against terrorists and the threat posed by hostile states," and "We must strengthen intelligence warning and analysis to provide integrated threat assessments for national and homeland security" (section IX).

The shift from a primarily reactive to a preemptive policy translates into two changes in the Taylor-Russell diagrams. First, the ellipse representing the uncertainty in the judgment context is larger under the new preemptive policy. Because a perceived threat level based on fallible intelligence is inherently less reliable than a perceived threat level based on past overt actions, the relationship between the perceived and actual threat will be weaker under a policy of preemption and represented as a wide ellipse in the Taylor-Russell diagram. Second, the decision criterion has been lowered, or moved to the left on the perceived threat axis. The new emphasis on taking action before threats are fully formed means that the United States will take action using a lower threshold of evidence than it has in the past. As noted in the introduction of this article, the 2002 NSS now states:

The United States can no longer solely rely on a reactive posture as we have in the past .... The greater the threat, the greater is the risk of inaction and the more compelling the case for taking anticipatory action to defend ourselves, even if uncertainty remains as to the time and place of the enemy's attack. (section V)

The Bush administration's shift in emphasis from a reactive to a preemptive policy can be represented in the Taylor-Russell diagram. The old and new policies are depicted in Figure 4.

Several logical conclusions can be made based on a comparison of the two Taylor-Russell diagrams representing the old reactive policy and the new preemptive policy (see Figure 4). First, notice that the increase in the width of the ellipse, coupled with the lowering of the criterion for military engagement greatly increases the number of total military engagements (events in the ellipse to the right of the vertical bar). Second, the judgment context is more uncertainty (the ellipse is wider) and therefore there will be an increase in the total number of judgment errors and an increase in disagreement about the interpretation of fallible indicators. Third, there is an increase in false positives relative to false negatives. Each conclusion will be addressed in more detail.

\section{Conclusion 1: Greater Military Engagement}

The lowering of the decision criterion means there will be an increase in military engagements (see Figure 4). The consequences of greater military engagement 
around the world are many. There will be an increase in lives lost (both U.S. and foreign). The United States will inevitably be viewed as more aggressive than it has been in the past. With an increase in military engagements will be a necessary increase in military costs and a greater portion of the U.S. national budget spent on the military. All three of these consequences have been borne out in the Iraqi preemptive attack. There continues to be a loss of life with no current sign that it is decreasing. There has been an increase in current world perception of the United States as an aggressor nation since invading Iraq. The costs of Operation Iraqi Freedom have been substantial and almost entirely funded by the United States.

\section{Conclusion 2: Greater Uncertainty in the Judgment Context Will Result in an Increase in Errors and Increased Disagreement About Fallible Indicators}

There are two bases for this conclusion. First, the lowering of the criterion for engagement, and second, the increased role of prediction means a greater reliance on fallible indicators, such as intelligence, and thus more inherent uncertainty in the judgment context, represented as a wider ellipse.

Since September 11, 2001, there has been much discussion about the difficulty of infiltrating terrorist networks for the purposes of obtaining intelligence. Because of the closed nature of their society, clandestine intelligence in the form of secret agents is difficult. The United States has relied on more technological forms of intelligence gathering that include satellite imagery and the interception of communications. More recently, the United States has also relied on intelligence obtained from "detainees." All these intelligence sources are fallible. They are ambiguous, often intentionally misleading, and subject to misinterpretation.

The reliance on fallible indicators may be largely to blame for the Bush administration's conclusion that Iraq had WMDs ready for use and that the United States knew the location of these weapons. Even before military engagement there was disagreement about the interpretation of indicators that Iraq had an active WMD program. For example, in his February 6, 2003, presentation to the United Nations, Secretary of State Powell acknowledged the disagreement inherent in interpreting these fallible indicators. He stated, "we all know that there are differences of opinion. There is controversy about what these tubes are for. Most U.S. experts think they are intended to serve as rotors in centrifuges used to enrich uranium. Other experts, and the Iraqis themselves, argue that they are really to produce the rocket bodies for a conventional weapon, a multiple rocket launcher." During the 2003 State of the Union speech, President Bush claimed that Iraq had tried to purchase weapons grade uranium from Africa, a claim that the administration later renounced as due to faulty intelligence. 


\section{Conclusion 3: An Increase in False Positives Relative to False Negatives}

Comparing the right half of the new and old policy diagrams reveals that the United States will be engaged in justified military action more often (correct positives). The increase in true positives is a good thing as it means more "evil-doers" will be caught and there will be fewer of them available to organize attacks against the United States and its interests. However, examination of the change in the lower right cell shows that the United States will also be engaged in unjust military action (false positives) more often. The increase in false positives is a result of shifting the criterion for military action to the left. Increasing the number of unjustified military actions will increase world perceptions that the United States is a threat to world peace. This could in turn result in more support for terrorist groups opposing the United States and consequently have the opposite effect desired by the United States. Richard Clarke (2004) wrote, "Instead of energetically pursuing the priority of creating an ideological counterweight for al Qaeda, we invaded Iraq and gave al Qaeda exactly the propaganda fuel it needed" (p. 273). One could argue that a similar consequence is what has taken place during the Israeli-Palestinian conflict. Israel has demonstrated it is willing to increase false positives (innocent casualties) to achieve the goal of more correct positives. This policy has led to increased support for the Palestinian militants by Palestinian civilians who feel unjustly punished by the Israelis. It is difficult, if not impossible, to determine if the increase in the correct positives, or the number of militants captured or killed, outweighs the increased support for militants (increased membership and funds) due to the increase in innocent casualties. Whether the increase in correct positives will outweigh the support that many anti-U.S. groups will receive as a result of increased false positives will be difficult to determine. As U.S. Secretary of Defense Donald Rumsfeld himself asked in a leaked memo, "Are we capturing, killing, or deterring and dissuading more terrorists every day than the madrassas and the radical clerics are recruiting, training, and deploying against us?" (Tucker, 2003).

The decision to invade Iraq can be viewed as a false positive, because the rationale for invasion, stockpiles of WMDs, has proven untrue. It is natural for an administration to wish to avoid the public perception of an error of this magnitude. This desire to save face likely accounts for the post hoc shift in the reasons why Iraq should have been considered a significant threat despite the post-invasion lack of evidence for stockpiles of WMDs. Before the invasion the Bush administration, via Secretary of Defense Rumsfeld's testimony to the House Armed Services Committee on September 18, 2002, argued that Iraq had "stockpiles of chemical and biological weapons" (Rosenberg, 2003). After invasion and the apparent failure to find stockpiles and active large scale production of WMDs, the Bush admin- 
istration has stressed that there were "weapons of mass destruction-related program activities" (Bush, 2004), a statement that is considerably less specific than their preinvasion statements.

The U.S. judgment of Iraq's WMD capabilities was clearly wrong and we have argued that this type of error is inevitable under the policy of preemption. How can the field of judgment and decision making help reduce errors of this magnitude?

\section{HOW CAN JUDGMENT ERRORS BE REDUCED?}

Flawed judgment can and has had profound effects on issues of war and peace. Flawed judgment was blamed for our failure to defend Pearl Harbor (Janis, 1982), which led to our direct involvement in WWII. Flawed judgment was blamed for our failure to foresee and prevent the attack on the world trade towers in New York on September 11, 2001 (The 9/11 Commission Report, 2004), which led directly to a U.S. invasion of Afghanistan. Flawed judgment was blamed for the inaccuracies in our prewar intelligence assessments of Iraq after Operation Iraqi Freedom failed to produce any evidence of an active Iraqi WMD program (Select Committee on Intelligence, United States Senate, 2004). Because the field of judgment and decision making has largely focused on judgment errors, it should be positioned to aid in the reasonable goal of reducing such errors in judgment.

Errors in judgment can be attributed to both cognitive and environmental factors. Errors of the cognitive nature include limits in our information processing system, which results in improper usage of the cues depicted in Brunswik's lens model (Figure 1). We might expect that training at the individual level could help reduce these types of errors. Indeed this approach has been taken by some members of the CIA Directorate of Intelligence. Richards Heuer (1999) wrote a series of articles during his long tenure at the CIA, which eventually culminated in a book, Psychology of Intelligence Analysis. The foreword of this book, by Douglas MacEachin, states, "Heuer makes clear that the pitfalls the human mental process sets for analysts cannot be eliminated; they are part of us. What can be done is to train people how to look for and recognize these mental obstacles, and how to develop procedures designed to offset them." The book is mainly focused on the application of cognitive principles (including the findings from the heuristics and biases program) to the craft of intelligence analysis. These tools, if successful, would result in a more accurate utilization of cues by experts. For example, one finding in judgment research is that cues learned first have an inordinately large emphasis placed on them. This is known as the primacy effect in judgment and results in under utilization of cues acquired later in time (Hastie \& Dawes, 2001). It is plausible that awareness of such a bias would help to immunize against its effects.

Errors that are attributed to environmental factors may be better addressed by making changes to the judgment context. Stewart (2000) argued that the best way 
to improve prediction and reduce errors is by improving environmental factors. He stated, "determining exactly how to change a particular environment requires a detailed analysis of that environment. Such an analysis addresses questions about the kind and amount of information available, how that information is organized, what the rewards or penalties are for good and bad decision, and requirements for justifying decisions, as well as many other factors" (p. 55). He suggests three elements of the environment that affect predictions:

1. "the nature of the system that is the object of prediction" (p. 51).

2. "the system that brings information about the external environment to the people making predications."

3. "the procedural, social, and bureaucratic context" in which the prediction is being made (p. 52).

Each element is briefly discussed with a focus on how it relates to the current policy of preemption and how errors might be reduced through changes to that part of the system.

There are several ways in which the "nature of the system that is the object of prediction" influences error. First, it is difficult for decision makers to learn under conditions of large uncertainty and infrequent feedback (Hammond, 1996; Stewart, 2000). Terrorist attacks on the United States are infrequent and unique enough to make feedback about decision quality rare and often ambiguous. This lack of feedback means that the improper use of indicators may go unchecked because determining what is and is not an error is ambiguous. Second, the United States shares a measure of responsibility for creating the "system that is the object of prediction" and contributing to structural violence through militarization. "[M]ilitarization continues to be an important source of structural violence, generating vast inequalities in coercive power and fuelling the potential episodes of violence, as big powers supply arms to smaller countries around the world" (Christie, Wagner, \& Winter, 2001, p. 10). The United States directly or indirectly funded both the military buildup of Saddam Hussein and Usama bin Laden. Militarization effectively increases the base rate of potential threats that are present in the ellipse of Figures 2, 3, and 4. Increasing the base rate of threatening groups increases the density in all four cells of the Taylor-Russell diagram and hence increases both types of error.

Effective long-term policies that address the root causes of terrorism would reduce the number of judgment errors by reducing the overall base rate of terrorist groups. The recent bill to overhaul U.S. intelligence (based largely on the recommendation from the 9/11 commission) explicitly includes a measure to "improve diplomacy by increased education and exchange programs with the Muslim world, promotes economic development efforts and maintains financial aid to Afghanistan and Pakistan" (Shenon, 2004, p. A19). Such efforts show that there is some 
awareness that effectively addressing structural causes of terrorism would reduce the base rate of terrorism. A decrease in the base rate for terrorism would be represented as a decrease in the density of events located within the ellipse on Figures 2, 3 , and 4 and would result in a lower number of cases in all four cells of the Taylor-Russell diagram.

Most public concern for reducing errors has focused on "the system that brings information about the external environment to the people making predictions." The dramatic reorganization of the federal government to now include a cabinet-level Department of Homeland Security was done partially to respond to claims that decision makers should have been able to foresee the attack of September 11, 2001, based on the available intelligence (O'Connell \& Tomes, 2003). The position of National Intelligence Director was created for the purpose of bringing reports together from the distributed intelligence agencies to policymakers. These changes to the intelligence community can be categorized into two groups: those that attempt to increase the accuracy of intelligence community predictions, which would shrink the width of the ellipse in the Taylor-Russell diagram and the number of both false positives and false negatives, and those that communicate the uncertainty within the intelligence community to policymakers. Communication of disagreement within the intelligence community over the interpretation of indicators provides policymakers with a better understanding of the fallibility of the indicators and hence, the potential for error.

The changes made to intelligence gathering, analysis, and reporting are also part of the "procedural, social, and bureaucratic context" of judgment. One aspect of how "the procedural, social, and bureaucratic" context influences error is what has often been referred to as the "corporate culture" within the CIA and the FBI. Clarke (2004), in his book Against All Enemies: Inside America's War on Terror, describes the risk-averse culture at the CIA as follows:

For those who had spent fifteen, twenty, or more years in CIA, there was a clear pattern: Whoever was in the White House would get worked up over the cause du jour. He would be unable to get the rest of the government to produce results, so he would turn to the CIA. He would push the CIA to do risky, potentially controversial things. Later, after things went badly, the White House people would be gone and CIA would get the blame. (p. 209)

It appears that the CIA reward structure encourages risk-averse behavior to ensure long-term survival within the CIA. Likewise, Clarke gives the impression that the reward structure within the FBI values criminal prosecutions. Terrorism is very time intensive for the number of successful prosecutions it yields. In terms of promotion, it was more fruitful for FBI officials to go after drug crimes than potential terrorists. Both the risk-averse culture in the CIA and the reward structure in the FBI would result in more false negatives relative to false 
positives. The reward system in both the FBI and the CIA are likely to be very different today than they were before September 11, 2001. It may be that today the bigger risk is false positives, such as the belief that Iraq had an ongoing WMD program, rather than false negatives.

\section{CONCLUSIONS}

There is a large body of empirical research based on Brunswik's lens model that examines judgments based on multiple fallible indicators (for some examples, see Hammond \& Stewart, 2001). This large body of research is now directly relevant to understanding our use of military force around the world, because the policy of preemption fundamentally rests on threat assessment via the use of multiple fallible indicators. This body of research offers great potential for increasing our understanding of the policy of preemption and its limits.

Likewise, the Taylor-Russell diagram helps explicate some of the implications of this policy. While there is considerably less research utilizing the Taylor-Russell diagram, we believe it is none the less useful in attempting to formalize and to understand how a strong preemptive policy differs from the more tradition reactive policy of the United States. In our discussions of the Taylor-Russell diagram we have focused on how the U.S. policy has changed the judgment context by altering the width of the ellipse and moving the decision criterion. Another important consideration, which we have not explicitly addressed, is how the system (terrorists and rogue states) may react to the policy of preemption. Clearly, there are dynamic components to this judgment context that have not been represented in our relatively static formalization. Future research could contribute to our understanding of these situation dynamics.

Perhaps the greatest clarification of the policy of preemption provided by the Taylor-Russell diagram is the duality of error. Arguments for a strong policy of preemption have understandably emphasized the high costs of false negatives. While we do not deny that these costs are real and important, we have tried to argue that the costs of false positives may be equally high. Perhaps the focus on false negatives and the neglect of false positives is partially due to something akin to the availability heuristics (Tversky \& Kahneman, 1982). The availability heuristic argues that people have a tendency to overestimate the likelihood of an event for which they have an available memory. The very salient and available memory of 9/11 should therefore result in people overestimating the likelihood of future terrorist attacks. This translates into not only overestimating likelihood but also overestimating costs. Although the long-term costs of false positives may be very high, people may not perceive them to be as high as false negatives. The true costs of the policy of preemption can only be fully understood by appreciating the duality of error and the inherent fallibility of threat assessment. 


\section{ACKNOWLEDGEMENTS}

Portions of this paper were completed while Philip Dunwoody was a Visiting Assistant Professor of Psychology at Mercer University, Macon, GA. Thanks to Keegan D. Greenier, PhD, Mercer University, for providing critical feedback on an early version of this manuscript. Portions of this research were presented in November 2004 at the Twentieth Annual International Meeting of The Brunswik Society, Minneapolis, MN.

\section{BIOGRAPHICAL NOTE}

Philip T. Dunwoody, PhD, is an Assistant Professor of Psychology at Juniata College, Huntingdon, PA. He teaches Political Psychology (listed within the departments of Psychology, Politics, and Peace and Conflict Studies), Judgment \& Decision Making, Cognition and Research Methods. His current research interests focus on applying the psychology of Judgment \& Decision Making to political behavior.

Kenneth R. Hammond, $\mathrm{PhD}$, is an Emeritus Professor at the University of Colorado, Boulder. His fields of interest included expert judgment, effects of stress on judgment, and conflict resolution in public policy making. He consulted for federal, state, and local governments and for multinational corporations. He is author of several books including Human Judgment and Social Policy: Irreducible Uncertainty, Inevitable Error, and Unavoidable Injustice and Judgments Under Stress.

\section{REFERENCES}

Adelman, L., Miller, S. L., Henderson, D., Schoelles, M. (2003). Using Brunswikian theory and a longitudinal design to study how hierarchical teams adapt to increasing levels of time pressure. Acta Psychologica, 112(2), 181-206.

Brunswik, E. (1952). The conceptual framework of psychology. Chicago: University of Chicago Press.

Bush, G. W. (2003, January 28). 2003 State of the Union address. Retrieved March 24, 2004, from http://www.whitehouse.gov/news/releases/2003/01/20030128-19.html

Bush, G. W. (2004, January 20). 2004 State of the Union address. Retrieved March 24, 2004, from http://www.whitehouse.gov/news/releases/2004/01/20040120-7.html

Christie, D. J., Wagner, R. V., \& Winter, D. D. (Eds.) (2001). Peace, conflict, and violence: Peace psychology for the 21st century. Upper Saddle River, NJ: Prentice Hall.

Clarke, R. A. (2004). Against all enemies: Inside America's war on terror. New York: Free Press.

Dunwoody, P. T., Haarbauer, E., Mahan, R. P., Marino, C., \& Tang, C. (2000). Cognitive adaptation and its consequences: A test of cognitive continuum theory. Journal of Behavioral Decision Making, 13, $35-54$.

Hammond, K. R. (1996). Human judgment and social policy: Irreducible uncertainty, inevitable error, unavoidable injustice. New York: Oxford University Press. 
Hammond, K. R., \& Stewart, T. R. (Eds.). (2001). The essential Brunswik: Beginnings, explications, applications. New York: Oxford University Press.

Hastie, R., \& Dawes, R. M. (2001). Rational choice in an uncertain world. London: Sage Publications. Herman, M. (2003). Intelligence power in peace and war. Cambridge: Cambridge University Press.

Heuer, R. J., Jr. (1999). Psychology of intelligence analysis. Washington, DC: Center for the Study of Intelligence, Central Intelligence Agency. Retrieved September 7, 2004, from http://www.odci. gov/csi/books/19104/index.html

Hollenbeck, J. R., Ilgen, D. R., Sego, D. J., Hedlund, J., Major, D. A., \& Phillips, J. (1995). Multilevel theory of team judgment making: Judgment performance in teams incorporating distributed expertise. Journal of Applied Psychology, 80, 292-316.

Janis, I. L. (1982). Groupthink (2nd ed). Boston: Houghton Mifflin.

MacEachin, D. (1999). Foreword. In R. J. Heuer, Jr., Psychology of intelligence analysis. Washington, DC: Center for the Study of Intelligence, Central Intelligence Agency. Retrieved September 7, 2004, from http://www.odci.gov/csi/books/19104/index.html

National Security Strategy of the United States of America (2002). Retrieved on January 13, 2004, from http://www.whitehouse.cog/nsc/print/nssall.html

O'Connell, K., \& Tomes, R. R. (2003, December). Keeping the information edge. Policy Review. Retrieved February 6, 2004, from http://www.policyreview.org/dec03/oconnell_print.html

Powell, C. (2003, February 5). Secretary of State Collin Powell addresses the UN Security Council. Retrieved March 24, 2004, from http://www.whitehouse.gov/news/releases/2003/02/20030205-1. html\#

Rosenberg, E. (2003, November 9). Rumsfeld retreats: Disclaims earlier rhetoric. StarBanner.com. Retrieved March 24, 2004, from http://www.starbanner.com/apps/pbcs.dll/article?AID=/20031109/ NEWS/211090375/1003

Select Committee on Intelligence, United States Senate. (2004). Report on the U.S. Intelligence Community's prewar intelligence assessments on Iraq: Conclusions. Retrieved July 12, 2004, from http://intelligence.Senate.gov/conclusions.pdf

Shenon, P. (2004, December 7). Accord reached on overhauling U.S. intelligence. The New York Times, pp. A1, A19.

Stewart, T. R. (2000). Uncertainty, judgment, and error in prediction. In D. Sarewitz, R. A. Pielke, \& R. Byerly (Eds.), Prediction: Science, decision making, and the future of nature (1st ed., pp. 41-47). Washington, DC: Island Press.

Taylor, H. C., \& Russell, J. T. (1939). The relationship of validity coefficients to the practical effectiveness of tests in selection: discussion and tables. Journal of Applied Psychology, 23, 565-578.

The 9/11 Commission Report. (2004). Final report of the National Commission on Terrorist Attacks upon the United States. Retrieved September 8, 2004, from http://www.9-11commission.gov/report/index.htm

Tucker, D. (2003, October). Rumsfeld's memo. Retrieved September 9, 2004, from http://www. ashbrook.org/publicat/oped/tucker/03/memo.html

Tversky, A., \& Kahneman, D.(1982). Availability: A heuristic for judging frequency and probability. In D. Kahneman, P. Slovic, \& A. Tversky (Eds.), Judgment under uncertainty: Heuristics and biases (pp. 163-178). Cambridge: Cambridge University Press. 